\title{
El tratamiento subversivo de los estereotipos de género y edad en la obra de Silvina Ocampo
}

\author{
Carolina SUÁREZ HERNÁN \\ IE Universidad
}

\begin{abstract}
RESUMEN
La narrativa de Silvina Ocampo muestra un importante énfasis en la dimensión social del ser humano. Los cuentos ofrecen un variado fresco de la sociedad argentina y de las relaciones interpersonales que en ella tienen lugar. Este artículo se centra en la subversión y transgresión que la autora lleva a cabo en torno a los estereotipos relacionados con el género y con la edad. La autora cuestiona y derriba el paradigma patriarcal mediante una deconstrucción sistemática del estereotipo femenino e, igualmente, somete la visión adultocéntrica del mundo a una profunda revisión en la que se revela la infancia como un dominio fantástico por explorar.
\end{abstract}

Palabras clave: Silvina Ocampo, género, infancia, transgresión fantástica, subversión, estereotipos.

The subversive treatment of the stereotypes of gender and age in Silvina Ocampo's work

\begin{abstract}
Silvina Ocampo's narrative conveys an important emphasis in the social dimension of human being. Stories present a general picture of Argentine society and of its interpersonal relationships. This article focuses on the subversion and transgression of the stereotypes related to gender and to age in Silvina Ocampo's narrative. The author questions and demolishes the patriarchal paradigm by means of a systematic deconstruction of the feminine stereotype and, likewise, she submits the adult-centric view of the world to a deep review in which childhood is revealed as a fantastic domain without exploring.
\end{abstract}

Key words: Silvina Ocampo, gender, childhood, fantastic transgression, subversion, stereotypes.

La obra de Ocampo mantiene una postura subversiva y crítica que encuentra placer en la transgresión. Los patrones establecidos se rompen y los roles son intercambiables; se someten a un tratamiento satírico las oposiciones estereotípicas de la femineidad y la masculinidad, la bondad y la maldad, la belleza y la fealdad. Igualmente, el espacio y el tiempo se subvierten y se borran los límites entre las categorías mentales de espacio, tiempo, persona, animal. El borrado de contornos va deconstruyendo los valores hasta afectar a todos los ámbitos de la realidad. La transmutación y la anomalía, así como los referentes afirmados y negados 
contribuyen al derribo de los cimientos de los esquemas tradicionales. La temática literaria tradicional referente al amor, los sentimientos, la crítica social, el ámbito familiar se aborda mediante enfoques transgresores. La hipocresía y la perversión vuelven ambivalentes todos los demás sentimientos; la sexualidad, la religiosidad y la malicia aparecen simultáneamente.

En esta constante ruptura de lo establecido, la realidad sufre distorsiones y los paradigmas de la cultura son sometidos a alteraciones que provocan una visión compleja y ambigua de la realidad. La narrativa ocampiana trata de derribar todos los axiomas y toda construcción jerárquica y dicotómica de la sociedad mediante múltiples recursos como la fantasía, el humor, la sátira y la parodia. Los estereotipos de género, de clase social y también los relativos a la edad se subvierten a partir de esta estética de la transgresión.

La literatura de Silvina Ocampo contiene una profunda reflexión sobre la feminidad y numerosas reivindicaciones de los derechos de la mujer, así como también una crítica sobre su situación en la sociedad. Son numerosas las aproximaciones a la obra de Ocampo desde ángulos feministas o desde análisis que parten de las especificidades de la literatura escrita mujeres. No obstante, existe una gran divergencia en la interpretación de los personajes femeninos. Por un lado, autoras como Noemí Ulla y Marcia Espinoza-Vera, destacan la libertad concedida a las mujeres y la independencia con la que actúan; los personajes femeninos son capaces de adoptar roles de dominación y de asumir decisiones propias (EspinozaVera 2003). Por el contrario, Mónica Zapata considera que el margen de actuación de las mujeres es muy limitado y que se circunscribe al papel de objeto sexual (Zapata 1992). Belinda Corbacho ofrece una lectura transversal de la obra de Ocampo para clasificar las distintas imágenes de mujeres; el imaginario femenino es muy variado y la autora encuentra distintos mecanismos de creación y deconstrucción de lo femenino (Corbacho, 1998).

Esta disparidad de opiniones en la crítica tiene su origen en la inmensa galería de personajes femeninos que muestran los cuentos de Ocampo y en la subversión ya mencionada de todos los patrones y estereotipos. Encontramos en los textos mujeres de clase social alta, numerosas féminas pertenecientes a la burguesía tanto alta como baja, y mujeres que integran el proletariado. Puede observarse un punto de vista amable ante las amas de casa, niñeras, costureras, peluqueras, planchadoras y, en general, todas aquellas que desempeñan trabajos para vivir. Además, muchas de estas mujeres están instaladas en una suerte de marginalidad: la pobreza, la exclusión social, la prostitución o el sometimiento. La mirada de Silvina hacia estas mujeres víctimas de la marginación es antropológica y descriptiva, en ocasiones tierna y poética. Así, por ejemplo, en "La escalera" encontramos a Isaura, una sirvienta que, mientras sube los escalones que siempre ha limpiado en busca de la ropa tendida en la azotea, recuerda en cada uno de ellos un momento de su vida y reflexiona sobre su existencia. El ascenso de la escalera es un viaje al pasado y cada peldaño supone una prueba material de su existencia. El relato nos muestra la 
conciencia de una mujer humilde que incluso desea una pequeña enfermedad para poder descansar. Igualmente, la narradora de "El sótano" cuenta en primera persona algunos aspectos de su vida pasada; a los once años recibía los restos de comida de las casas lujosas, siempre ha vivido en la marginación de la miseria. En el presente es prostituta y vive en un sótano sin ninguna comodidad y junto a ratones a los que ha puesto nombre y a los que alimenta. Fermina se siente acosada y espiada por los demás; su discurso incoherente parece el de una mujer perturbada. El sótano va a ser demolido y Fermina se verá obligada a salir al exterior, pero ella ha resuelto vivir siempre en la marginalidad en la que siempre ha estado.

Ahora bien, las mujeres burguesas y aristócratas son objeto de una feroz sátira en la mayoría de los casos. Algunos relatos ofrecen una visión de la feminidad como un engaño y una creación artificial, como "Los celosos", "Las vestiduras peligrosas" o "La propiedad". Son muchos los personajes femeninos que hacen cualquier cosa para satisfacer el deseo masculino y que intentan justificarse constantemente para mantener una imagen de ingenuidad o de pasividad. Abundan también las mujeres que perpetúan los estereotipos y son incapaces de desafiar las reglas, como las señoras de "Las esclavas de las criadas" o la protagonista de "El crimen perfecto". Por otro lado, la autora muestra mujeres mentirosas, manipuladoras, superficiales y perversas. La mayor parte de las narradoras y protagonistas de los cuentos carecen de credibilidad y muestran hipocresía, cinismo o crueldad en sus discursos. Por ejemplo, las narradoras de "Las fotografías", "El chasco" y "El incesto" muestran una pérfida crueldad, mientras que "La oración" ofrece el mejor ejemplo de hipocresía. En este último, hay un narrador extradiegético que comienza el relato situando a la protagonista en la iglesia rezando; el resto del relato es el discurso que ella dirige a dios. Laura no es una mujer piadosa que va a rezar sino que es una mujer falsa y adúltera que se oculta en el confesionario a la espera de que se realice el asesinato de su marido. La mujer no confiesa sus verdaderos motivos aunque queda claro su deseo de volver a ser soltera; insiste en informar al narratario de sus sufrimientos y de sus buenas intenciones mientras planea el crimen de su marido.

Así mismo, se ofrecen casos de mujeres destructivas y autodestructivas; las disputas entre mujeres alcanzan un alto grado de violencia, como en "Rhadamantos" o "La furia". El sacrificio personal en forma de suicidio como venganza o rebelión aparece en "Carta perdida en un cajón” donde la narradora decide su propia muerte para asegurarse de que su rival siempre será infeliz. "El lazo" muestra a una mujer joven que trabaja en un dispensario médico y que relata la complicada relación que tiene con una compañera de trabajo, Valentina Shelder. Valentina es anciana, distinguida y adinerada; la narradora dice que trabaja sin estar llevada por la necesidad, lo que hace inferir a los lectores que pertenece a una clase social superior a la de la narradora. La relación entre ambas mujeres es muy tensa; la narradora acusa a Valentina de haberla convertido en un monstruo y la llama chismosa y arrogante. Se expresa en un lenguaje coloquial y, en ocasiones, 
irreverente; relata múltiples situaciones en las que Valentina se muestra cruel y ambas se enfrentan con sartas de insultos: "Lengua larga. Mula. Yegua. Cretina. Degenerada. Infeliz". El odio que se profesan las mujeres acaba con el asesinato de Valentina, después de que ésta acusara a la narradora de "inmoralidad, de perversión, de latrocinio, de mendacidad, de crueldad” y de mantener relaciones amorosas con uno de los médicos. La escena final está cargada de tensión y de truculencia: la narradora le clava a Valentina un bisturí en el cuello y la sangre se derrama mientras suena la risa estridente de la víctima.

Las narradoras femeninas son presentadas como personajes más crueles e insensibles que los masculinos y aquellas mujeres que tienen opiniones y deseos propios se convierten en extraños monstruos para los otros personajes. Ocampo crea mujeres complejas y ambiguas; la duplicidad del personaje femenino se muestra a través de recursos como el artificio y de la máscara. Los relatos presentan el lado oscuro de la feminidad; la múltiple representación femenina muestra una ambigüedad que anula la visión unidimensional del personaje femenino (EspinozaVera, 2003: 211). La autora se rebela ante las limitaciones impuestas a las mujeres $\mathrm{y}$, por ello, cuestiona los arquetipos e invierte la imagen tradicional de la mujer. La metamorfosis y la animalización aparecen como procesos de reconstrucción del cuerpo femenino a través de lo fantástico. Las metamorfosis de "Isis”, "Malva”, "La peluca" y, sobre todo, la de "Keif” aparecen como creaciones de una imagen nueva de la imagen femenina a partir de la transgresión fantástica. La protagonista de este cuento, Fedora, vivía en compañía de un tigre llamado Keif al que adoraba. Ha decidido suicidarse para renacer en el cuerpo de una amazona de circo o una domadora y explica que el suicidio será agradable y que su idea de cambiar de vida es firme porque está saturada de la suya. La metamorfosis de Fedora se manifiesta como un deseo cumplido y como una posibilidad de acceder a la vida anhelada.

Patricia Kingenberg ofrece un análisis cercano al feminismo de los cuentos de Ocampo dentro de los contextos del grotesco y de lo fantástico (Klingenberg, 1999). La autora desglosa una serie de elementos temáticos sobre la mujer que conectan con la obra de Ocampo, a saber, lo subversivo, la magia, la transgresión de los espacios de la mujer como madre, la perversión sexual, el discurso epistolar y los dobles femeninos.

En esta línea, puede destacarse que, en la obra de Ocampo, la magia y la fantasía son elementos de subversión femenina. Los temas fantásticos se desarrollan en un ámbito de marginalidad, en la liminalidad de lo establecido; por ello la feminidad y la infancia son espacios propicios para la deconstrucción de estereotipos y la creación de nuevos órdenes mediante recursos fantásticos. Son numerosos los cuentos en los que algún personaje femenino posee el don de la adivinación; por ejemplo, "Autobiografía de Irene", "La muñeca", "La sibila”, "Los sueños de Leopoldina”, "Soñadora compulsiva”, entre otros. "La muñeca” un buen ejemplo de la unión de la magia y la marginalidad. Se trata de un relato narrado en primera persona y de manera retrospectiva, esto es, la narradora comienza su historia desde 
su condición de adivina y de mujer adulta, que rememora el desarrollo de su don y su infancia. La protagonista es una mujer muy humilde, sin nombre propio, que sufrió el abandono de su familia y la exclusión social durante toda su vida. La marginación y la carencia afectiva suscitan una fantasía extraordinaria en la niña, que pronto empieza a mostrar sus dotes adivinatorias. El cuento termina en el momento en que la niña describe minuciosamente una muñeca que va a recibir en el momento de su consagración como bruja. El estatus de adivina es, en buena parte, dictado por aquellos que rodean a la narradora y que la convierten en un elemento alterizado; pero ella se apropia de la magia para conformar su identidad futura.

Así mismo, las mujeres y los niños se encuentran siempre cerca de los actos crueles; los personajes femeninos son perversos y capaces de asesinar. La violencia ejercida por mujeres genera la extrañeza, debido a la oposición a los paradigmas tradicionales de género en torno a la mujer pasiva, cooperativa y cuidadora. Las niñas son propensas a la maldad; las madres son controladoras, negligentes, terribles, adúlteras. Las madres que aparecen en "Voz en el teléfono" y "El goce y la penitencia" engañan a sus maridos y desatienden a sus hijos. El fantasma de Clotilde Ifrán, protagonista del cuento que lleva su nombre, es madre sustituta debido al abandono de la niña por parte de su madre verdadera.

En "El retrato mal hecho" se describe a una familia burguesa en la que destaca Eponina, una madre representativa de una clase social de moral y costumbres arraigadas, más preocupada por la moda que por sus hijos. Eponina es distante, fría e indiferente, "detestaba los chicos, había detestado a sus hijos uno por uno a medida que iban naciendo"; su vida transcurre, abúlica, mientras lee revistas. Ana es la sirvienta y la madre sustituta que trabaja incansablemente y el único refugio de los niños, que son víctimas de la insatisfacción de su madre. Un día Ana no está para servir la comida y es sorprendida en el altillo junto al cadáver de uno de los niños medido en un baúl. El asesinato del niño llevado a cabo por la sirvienta horroriza a la familia y provoca en Eponina una extraña reacción: se abraza a la sirvienta con "un gesto inusitado de ternura" y la consuela. Por un lado, el abrazo solidario sugiere que ambas mujeres tienen en común el sometimiento a un sistema de valores que limita la vida de las mujeres dejándolas sin voluntad; por otro, el abrazo convierte a Ana en brazo ejecutor de Eponina inscribiendo a las mujeres en la figura del doble al disolver sus individualidades (Mancini 2003: 266). Al igual que en otros casos, el narrador omnisciente adopta una postura ambigua ante los hechos y no ofrece ninguna valoración.

Puede observarse una parodia incesante del paradigma patriarcal y del estereotipo femenino mediante la apropiación del discurso propio de los hombres y la ambivalencia de género en las voces narrativas. Son frecuentes las transformaciones de género y los relatos en los que las convenciones genéricosexuales deben operar como determinantes de sentido. La práctica del mal concede a las mujeres de los relatos ocampianos gran protagonismo y supone una puesta en solfa de la oposición paradigmática de los sexos. Las mujeres de los cuentos distan 
mucho de la actitud pasiva e inofensiva reservada a las mujeres en la tradición literaria; por el contrario, los personajes femeninos de Ocampo llevan a cabo actos que tienen consecuencias y que dejan marcas profundas (Ostrov, 1996).

Andrea Ostrov analiza la construcción del género en la obra de Ocampo y muestra un posible cuestionamiento de lo que significaría "escribir como una mujer”. Parece claro que el género es una categoría superpuesta al sexo como un constructo social. Así, los textos plantean una cierta oposición a la postura esencialista del feminismo ofreciendo versiones de la feminidad muy diferentes. Los cuentos de Ocampo muestran una concepción de la subjetividad genérica como construcción vinculada al artificio y a la confección (Ostrov, 2004). La autora toma el pensamiento dicotómico que establece la diferencia sexual y establece los paradigmas de género para así deconstruirlos.

Los hombres son menos numerosos y cobran menos protagonismo en la obra de Ocampo. Las metamorfosis sufridas por los hombres no son deseadas, ya que ellos no manifiestan voluntad de salir de sus cuerpos. Además, los pocos personajes masculinos que poseen el don de la adivinación son niños, como Maguh, o discapacitados, como Valentín Brumana. Algunos hombres aparecen en el lugar de narradores y presentan a los personajes femeninos como seres misteriosos o salvajes; muestran también rasgos de perturbación mental, como los narradores de "La casa de azúcar" y "El automóvil”. Este cuento presenta a un hombre obsesionado por su esposa y preso de una aguda celopatía. El narrador es el protagonista de la historia, que narra cómo su esposa, Mirta, siente una pasión desmedida por los coches hasta el punto de convertirse en uno y marcharse sin él. Hay que destacar que el interés de Mirta por los coches altera la distribución de roles genéricos, sus gustos y aficiones no son propias de una mujer, lo cual exaspera a su esposo.

"Mi amada” tiene también un narrador masculino y presenta, además, uno de los símbolos mágicos de la feminidad más reiterados en la literatura. El cuento tiene como tema una relación amorosa en la que un elemento femenino cobra una importancia especial: la cabellera. El narrador recuerda la figura de su amada Verónica; pero sólo su pelo le hace olvidar el mal que supuso el abandono y la traición. El hombre repasa las cabelleras famosas de la historia y de la mitología, así como algunos de los símbolos referidos al atributo femenino. Fue precisamente la obsesión por el cabello lo que provocó la ruptura entre los amantes; el hombre, celoso de la atención de su amada, intentó estrangularla anudando alrededor de su cuello los largos cabellos. Así, la autora muestra a la mujer víctima y esclava de su feminidad, que sirve para doblegar la voluntad de los hombres pero que puede causar la desgracia.

Por otro lado, en la narrativa de Ocampo, la infancia es el espacio sagrado y mágico en el que se privilegian otras estructuras de poder y se subvierten los modos de organización social establecidos. José Bianco destaca el asombro del lector ante la atmósfera mágica en la que se desarrollan algunos de los relatos y el hallazgo de 
la infancia como espacio en el que puede recobrarse todo lo misterioso y ambiguo. "Silvina Ocampo nos pone de nuevo en contacto con los sufrimientos exquisitos de la niñez, con todo lo misterioso y equívoco que hay en su pureza" (Bianco 1988: 149). Por su parte, Fiona Mackintosh también señala la exploración de los traumas de la infancia y el paso de la niñez a la edad adulta en la obra de Silvina Ocampo y de Alejandra Pizarnik; la infancia se redefine en sus textos como un "dominio ilícito" fascinante en el que la transgresión y la inocencia se pueden aunar. Así, por ejemplo, las muñecas aparecen profusamente en la obra de ambas como elemento inquietante relacionado con la identidad, la sexualidad y lo ominoso (Mackintosh, 2003:63).

Los personajes infantiles son muy numerosos; en muchos casos se trata de niños de entre siete y once años de edad. Estos pequeños son representantes de la marginalidad tan presente en la obra de Silvina Ocampo. El territorio de la infancia es propicio para la irrupción de lo extraño o lo siniestro porque, como afirma la autora en el relato "Fidelidad", sólo la infancia mantiene secretos inviolados. Hay en la obra de Silvina una visión de la infancia cercana a lo mágico; la mirada infantil transgrede los límites de la estructura tradicional y los descubre. Así, por ejemplo, en "La música de la lluvia” y "La lección de dibujo", la edad es un secreto relacionado con la locura y, sobre todo, con el rechazo de la realidad que la autora se cuestiona constantemente. Los niños observan el mundo sin los prejuicios propios del mundo de los adultos, representan la inocencia. Los personajes infantiles son a menudo víctimas de la crueldad de los adultos, pero también manifiestan comportamientos crueles. La ambigüedad se mantiene siempre con respecto a la responsabilidad y la conciencia de los niños sobre sus actos crueles, como en "El vendedor de estatuas", en el que un adulto tiene un miedo inexplicable a un niño de siete años, que termina matándolo como respuesta a la indiferencia que el desprecio con el que lo ha tratado.

La voz narrativa infantil se convierte en una estrategia para generar la ambigüedad que parte del narrador poco fiable ya que el lector siempre alberga dudas sobre el grado de comprensión de los hechos por parte del narrador así como sobre su credibilidad. Es frecuente la descripción de hechos atroces a través de la mirada infantil, como en "La casa de los relojes", o "Cielo de claraboyas". Igualmente, en "La boda" encontramos una narradora infantil, Gabriela, una niña de siete años, que siente una profunda admiración por su amiga Roberta, de veinte años. Una prima de esta última, Arminda, va a casarse y la narradora cuenta que la noche anterior a la boda había encontrado una araña venenosa y la había guardado en una caja que Roberta le facilitó. A la mañana siguiente, en la peluquería, tiene la ocurrencia de colocar la araña en el rodete del peinado de la novia. La narración mantiene hasta el final la ambigüedad acerca de la responsabilidad de Roberta en la muerte de Arminda, así como las dudas sobre la inocencia de la niña cuando decide colocar la araña que causó la muerte de la chica. Las contradicciones del relato hacen imposible establecer las culpas y los motivos. 
Blas Matamoro, en su artículo "La nena terrible", postula que Ocampo se centra en los seres marginados socialmente: niños, mujeres, sirvientes y ancianos. Además, analiza la alianza que se establece entre los personajes infantiles y los miembros de una clase social desfavorecida (Matamoro, 1975). Los niños terribles se han tenido que educar en una cultura represiva y han sufrido el desafecto de la familia. Así mismo, el abandono familiar se suple con el cariño del grupo social de la servidumbre al cual son confiados. La mayoría de los personajes infantiles de Ocampo son niños terribles. Los cuentos muestran la asimetría entre el mundo de los adultos y el mundo infantil; los padres, maestros e institutrices encarnan la institución sancionadora y son con frecuencia figuras nefastas. Los niños terribles son la respuesta contra el mundo represivo y la impotencia afectiva; por lo tanto, la ambigüedad en los sentimientos de los hijos hacia los padres y viceversa es constante. La nena terrible sufre una doble condición que propicia su exclusión: es mujer y es terrible; la represión la llevará a padecer el castigo y la culpa por sus actos de rebeldía. La nena terrible se alía con objetos mágicos y con prácticas marginales para ahuyentar la soledad:

La nena terrible, cargada de tensiones reprimidas, identificada con personajes del margen social, encuentra en los seres-tabú el primer motivo del asombro místico, así como encontrará en los objetos prodigiosos el segundo motivo de satisfacción imaginaria para sus deseos reprimidos. Lo que no puede hacer por sí misma, por estar inscrita en el sistema de prohibiciones impuestas, lo harán por ella los santos imbéciles y las cosas mágicas. (Matamoro, 1975:205)

La nena terrible se convierte en la niña impura; la ruptura de los tabúes acarrea traumas para la niña educada en el catolicismo y en la élite social (Araújo, 1984). La religión convierte el cuerpo en algo degradado y la niña impura sufre las consecuencias de la exaltación de los falsos pudores. La transgresión condena a la impureza a la pequeña protagonista de "El pecado mortal", que pertenece a un círculo social que rinde culto a la disimulación. Así mismo, se vincula el aislamiento de la niña con el despertar de la sexualidad, ya que la niña llena el vacío de su carencia afectiva con el violador. Este cuento relata la violación de una niña presentando el hecho con ambigüedad en cuanto a la responsabilidad que le corresponde a la pequeña. La narración está a cargo de una mujer adulta que se dirige a un tú infantil; parece que hay un desdoblamiento en el sujeto de la enunciación y que se dirige a ella misma cuando era niña. La víctima es miembro de una familia burguesa acomodada con unos padres despreocupados que dejaban a la niña a cargo de su violador. La relación que se establece entre la niña y el sirviente parece ser más de seducción que de violencia; la niña parece sentirse atraída por el hombre o, al menos, le provoca curiosidad que hace que esté siempre pendiente de todo lo que hace. El suceso marca la vida de la niña, que sobrevive llena de culpabilidad y atormentada durante numerosas noches de insomnio. La 
narradora cuenta los hechos de modo que los lectores tienen la impresión de que la responsabilidad es compartida tanto por el violador como por la niña.

Las nenas terribles son niñas desvalidas expuestas a un mundo implacable por lo que desarrollan cierta propensión a la maldad o a la manipulación. Los niños están en posición marginal debido a las carencias y diferencias físicas o de personalidad. Las mujeres, los niños y los pobres comparten una posición subalterna en la estructura social que se fragua a partir de los estereotipos de dominación y poder. Son numerosos los cuentos en los que los miembros de grupos degradados o sometidos comparten protagonismo. Así, por ejemplo, los niños que se acercan a la pobreza y se sienten turbados y atraídos por ella son frecuentes. "Los enemigos de los mendigos" es relato escrito en verso cuya anécdota es sencilla: la descripción de los mendigos, el color de su piel, sus ropas, sus costumbres y el comportamiento de la gente cerca de ellos. Una niña siente curiosidad por vagabundos y se acerca a ellos para hablar.

Ahora bien, la incomunicación y la inaccesibilidad entre mundos diversos se muestran en la dicotomía establecida entre el mundo de los adultos y el de la infancia. En "Esperanza en Flores”, la viuda Esperanza y el niño Florián se refugian el uno en el otro de sus respectivos entornos, la soledad y la miseria respectivamente; pero su unión es efímera y la imposibilidad de comunicación se instala entre ellos. "El remanso" presenta, igualmente, la abrupta separación entre clases sociales y grupos de edad. En este relato, las dos hijas del cochero Venancio Medina participan de la vida de los dueños y juegan con sus hijos. A medida que pasa el tiempo y se alejan de la infancia, Libia y Cándida, las hijas del empleado, pierden la amistad de los propietarios, se ven expulsadas del entorno cálido en el que habían crecido y huyen en busca de otro orden en el que tampoco serán felices. "Las dos casas de los olivos", "La siesta en el cedro" y "Día de santo", entre otros relatos, presentan la misma impermeabilidad entre el mundo de los adultos y el mundo de la infancia.

Por otro lado, se atribuye a los niños características tales como la inocencia y la mirada prístina, de las cuales la autora se sirve para trastocar las categorías a partir de las cuales los adultos organizan el mundo (López-Luaces, 2001: 65). Ocampo privilegia la infancia sobre la edad adulta como espacio apropiado para subvertir las estructuras sociales; así, la mirada infantil será el instrumento para socavar las bases estructurales y transgredir los límites establecidos. Las estructuras de poder son objeto de reflexión y el punto en el que se concentran los esfuerzos de transgresión. Es frecuente que los niños tomen el poder por medio de la crueldad y la perversidad; la maldad institucional es ejercida por los adultos y los actos crueles protagonizados por niños producen una visión alternativa de la realidad. La perversidad infantil genera un fenómeno extraño y es una fuerza creadora para los niños. Los niños perversos son muchos, como la protagonista de "La hija del toro", la narradora de "El árbol grabado", la niña Winifred y, sobre todo, la inteligente y pérfida Porfiria, que inflige a su institutriz un destino fatal. En "El diario de Porfiria 
Bernal” encontramos la capacidad de modificar el mundo a través de la palabra escrita; la niña posee el poder de adivinar el futuro, de leer los pensamientos de los adultos y de provocar una metamorfosis. Los adultos permanecen ajenos a los poderes de la niña y al pánico que esta genera en la maestra. El relato mantiene la ambigüedad hasta el final porque Miss Fielding podría ser una perturbada que cree ver en Porfiria una posesión diabólica. En todo caso, los poderes atribuidos a la niña y su perversidad generan perturbación en el lector que no puede evitar identificarse con la mujer adulta.

Los niños discapacitados aparecen como seres visionarios con una percepción trascendental que va más allá de la lógica; así ocurre en “Tales eran sus rostros” y "Ana Valerga”. En otras ocasiones los visionarios no tienen ninguna discapacidad mental, como Magush o Irene, pero su carácter especial marca sus vidas y sus relaciones con los demás. Los niños también se relacionan también entre ellos como en "La siesta en el cedro", "Los amigos" y "Las dos casas de los olivos". La metamorfosis es un modo más de desestabilizar la posición de los adultos como en "Isis" y en "La soga" donde la fuerza creadora de un niño propicia la conversión de un objeto en un animal. "Icera” y "El bosque de los helechos" muestran personajes femeninos incapaces de crecer y convertirse en mujeres adultas.

La diferencia física y de edad como base para establecer el poder se cuestiona subvirtiendo la oposición entre niño y adulto en "La raza inextinguible" donde se muestra un mundo al revés en el que los niños ejercen la posición dominante. En este cuento, un narrador encuentra un lugar en el que todo es "perfecto y pequeño" y supone que una raza evolucionada de pigmeos la habita. Un muchacho le explica que todo está dispuesto a la medida de los niños porque son ellos quienes organizan todos los aspectos de la sociedad y trabajan mientras los adultos juegan a las cartas, conversan, aman y odian. En este mundo todos están destinados a mantenerse en una infancia indefinida, si bien a los niños les preocupa que los adultos quieran volver a ocupar el lugar privilegiado que han perdido para siempre. Las últimas palabras del relato afirman que esta inversión puede suponer un cambio en la perspectiva sobre el mundo: "Es verdad que algunos, entre nosotros, afirman que al reducirnos, a lo largo del tiempo, nuestra visión del mundo será más íntima y más humana” (Ocampo, 1999:306).

Silvina Ocampo muestra en su narrativa una inmensa galería humana a través del distanciamiento de la mirada antropológica. Los relatos presentan un registro minucioso de comportamientos, sentimientos, pasiones, amores, odios y obsesiones que abarca todos los órdenes sociales. De hecho, podrían entenderse como una suerte de tratado acerca de los sentimientos que entran en juego en la comunicación y aquellos que afectan al interior del individuo y su relación con el mundo exterior. No obstante, a pesar del interés de la autora por el mundo íntimo y psicológico de los personajes, resulta de mayor relevancia en este punto su vertiente social e interpersonal. 
En general, podemos afirmar que la autora lleva a cabo una exhaustiva observación de las relaciones de dominación y poder en la sociedad argentina. Los cuentos presentan prototipos de dominadores y dominados, así como diversas situaciones en las que se ejerce el poder establecido y coercitivo y la resistencia frente a este. Así, por ejemplo, la violencia es un elemento a través del cual se ejerce el poder y también un instrumento de resistencia. Los personajes ignoran las nociones del bien y del mal, ya sean víctimas o victimarios. Ejercen la crueldad los adultos, tanto hombres como mujeres, así como también los niños muestran comportamientos perversos y crueles. La crueldad de los adultos se percibe como cotidiana e institucionalizada, sobre todo la ejercida por hombres. Las mujeres muestran tendencias agresivas y la crueldad que ejercen está relacionada con la marginalidad, excepto cuando se trata del trato vejatorio o el abandono de los hijos. La crueldad en la infancia tiene tintes subversivos, los niños toman el poder mediante la perversidad o la violencia. Así mismo, Ocampo revela otros elementos a través de los cuales los marginados y los débiles se oponen a la dominación y al orden imperante. Los relatos ofrecen órdenes superpuestos en los que la jerarquía y la dominación son invertidas por la parodia o por la fantasía. En los espacios de liminalidad y en los márgenes de la sociedad se invierte el poder y los marginados se apropian de él mediante la inversión carnavalesca, el grotesco, el humor, la imaginación y la fantasía.

\section{BIBLIOGRAFÍA}

ARAÚJO, Elena.

1984 “Ejemplos de la 'niña impura’ en Silvina Ocampo y Alba Lucía Ángel”, Hispamérica, vol. 13, nº 38, págs. 27-35.

BIANCO, José.

1988 “Viaje olvidado”, en Ficción y reflexión. México: FCE, pp. 19481949.

CORBACHO, Belinda.

1998 Le monde femenin dans l'ouvre narrative de Silvina Ocampo. París: L'Harmattan.

ESPINOZA-VERA, Marcia.

2003 La poética de lo incierto en los cuentos de Silvina Ocampo. Madrid: Pliegos.

KLINGENBERG, Patricia.

1999 Fantasies of the Feminine. The Short Stories of Silvina Ocampo. London: Associated University Press.

\section{LÓPEZ-LUACES, Marta.}

2001 Ese extraño territorio: la representación de la infancia en tres escritoras latinoamericanas. Santiago: Cuarto Propio. 
MANCINI, Adriana.

2003 Silvina Ocampo. Escalas de pasión. Buenos Aires: Norma.

MACKINTOSH, Fiona J.

2003 Childhood in the Works of Silvina Ocampo and Alejandra Pizarnik. Woodbridge: Tamesis.

MATAMORO, Blas.

1975 "La nena terrible", en Oligarquía y literatura. Buenos Aires: Ediciones del Sol, pp. 193-221.

OCAMPO, Silvina.

1999 Cuentos completos I y II. Buenos Aires: Emecé.

OSTROV, Andrea.

1996 "Vestidura/escritura/sepultura en la narrativa de Silvina Ocampo", Hispamérica, $\mathrm{n}^{\circ}$ 74, pp. 21-28.

2004 El género al bies. Cuerpo, género y escritura en cinco narradoras latinoamericanas. Córdoba: Alción Editora.

ZAPATA, Mónica.

1992 L'esthétique de l'horreur dans les recits courts de Silvina Ocampo. Tesis doctoral. Université de Tolouse Il-Le Mirail. 